\title{
ENSINO REMOTO EMERGENCIAL: AÇÕES E REALIDADE VIVENCIADA POR ESTUDANTES DO 9 N ANO DE UMA ESCOLA PÚBLICA NA DISCIPLINA LÍNGUA PORTUGUESA
}

\author{
Dijanice Maria Ferreira da Silva Andrade ${ }^{1}$ \\ Amanda Micheline Amador de Lucena ${ }^{2}$ \\ Maria Josiane Lira do Nascimento ${ }^{3}$ \\ Josiane Maria da Silva ${ }^{4}$
}

RESUMO: Diante da pandemia causada pelo COVID-I9, vários setores da sociedade por algum momento tiveram que fechar suas portas ou se ajustarem para continuar funcionando, inclusive as escolas precisaram tomar medidas para que os estudantes não perdessem o ano escolar sendo que, para isso foi necessário criar medidas para restringir aglomerações e adotar o distanciamento social. Dentre as medidas adotadas no Brasil para que os estudantes continuassem o processo de escolarização, destaca-se o Ensino Remoto Emergencial (ERE) no qual estudantes assistem aulas remotas e desenvolvem atividades extra mantendo o distanciamento social. Com esse novo modelo de ensino, muitos desafios surgiram e assim, com este estudo buscou-se descrever a frequência com que os estudantes os estudantes do $9^{\text {o }}$ ano interagem com as ações vinculas ao Ensino Remoto Emergencial e se consideram que as aulas de Língua Portuguesa assistidas no ambiente online são eficiente de forma que favorecem a aprendizagem. Para isso uma pesquisa de campo foi desenvolvida em uma Escola Pública localizada no interior do Estado de Pernambuco. Os sujeitos pesquisados foram estudantes do $9^{\circ}$ ano e o instrumento para coleta de dados foi o formulário, o qual foi preenchido através do aplicativo Google forms. Percebe-se que existe uma falta de motivação por parte dos estudantes para participarem ativamente e frequentemente das ações vinculadas ao ERE e, espera-se adquirir novas compreensões sobre o processo de ensinar e mediar a aprendizagem de forma remota, considerando as estratégias que tem apresentado bons resultados e àquelas que precisam ser repensados para tornar o ERE mais eficiente. O estudo contribui para uma reflexão quanto a essa forma de ensinar e aprender e, a partir disso ir em busca estratégias que possam estimular a motivação dos estudantes para se envolverem de forma mais efetiva no processo de ensino e aprendizagem.

Palavras-chave: Aulas Remotas. Distanciamento social. Interação.

ABSTRACT: After of the pandemic caused by COVID-I9, various sectors of society for some time had to close their doors or adjust to continue functioning, including the schools

\footnotetext{
Mestranda do Curso de Ciências da Educação da Veni Creator Christian University. E-mail: ferreiraandradevccu@gmail.com.

${ }^{2}$ Doutora em Recursos Naturais e Professora do Curso de Mestrado e Doutorado em Ciências da Educação pela Veni Creator Christian University. E-mail: amandamicheline@hotmail.com

3 Mestranda do Curso de Ciências da Educação da Veni Creator Christian University. E-mail: josiane.lira2or8@gmail.com

4 Mestranda do Curso de Ciências da Educação da Veni Creator Christian University. E-mail: josianemarcelo_33@hotmail.com
} 
needed to take measures so that students did not miss the school year, and for this it was necessary create measures to restrict agglomerations and adopt social distance. Among the measures adopted in Brazil for students to continue the schooling process, Emergency Remote Education (ERE) stands out, in which students attend remote classes and develop extra activities while maintaining social distance. With this new teaching model, many challenges arose and so, with this study we sought to describe the frequency with which students and 9 th grade students interact with actions linked to Remote Emergency Teaching and Portuguese Language classes are considered to be assisted in the online environment they are efficient in ways that favor learning. For this, a field research was carried out in a Public School located in the interior of the State of Pernambuco. The researched subjects were 9 th grade students and the instrument for data collection was the form, which was completed using the Google forms application. It is noticed that there is a lack of motivation on the part of students to actively and frequently participate in the actions linked to the ERE and, it is expected to acquire new understandings about the process of teaching and mediating learning remotely, considering the strategies that have been presented good results and those that need to be rethought to make the ERE more efficient. The study contributes to a reflection on this way of teaching and learning and, based on that, looking for strategies that can stimulate the motivation of students to become more effectively involved in the teaching and learning process.

Key words: Remote Lessons. Social Distancing. Interaction.

\section{INTRODUÇÃO}

A partir do ano de 2019, o mundo vivenciou a pandemia causada pelo Covid-19 e isso causou e vem causando inúmeros impactos negativos sobre a vida humana e modo de vida das pessoas. Com a pandemia, os diversos setores da sociedade tiverem que parar ou se ajustarem para continua seu trabalho e não obstante, o setor educacional. Contudo, para minimizar os impactos trazidos ao setor educacional, muitas instituições adotaram o modelo de Ensino Remoto Emergencial e é possível afirmar que a mudança que talvez ocorresse na educação em uma década acabou acontecendo de forma "emergencial" em um, dois ou três meses, assim o ensino convencional onde aconteciam aulas presenciais foi repentinamente substituído pelo Ensino Remoto Emergencial.

De acordo com Behar (2020) é preciso diferenciar, neste momento, que a maior parte das instituições de ensino não está fazendo Educação a Distância, e sim o Ensino Remoto Emergencial e essa transição para ERE que a escola teve que passar de forma repentina, tem exigido dos docentes o "processo de planejamento, criação, adaptação dos planos de ensino, o desenvolvimento de cada aula e a aplicação de estratégias pedagógicas online"(p.5).

De forma geral, as escolas públicas do Estado de Pernambuco vêm se adaptando ao ERE de acordo com suas limitações e possibilidades de promover um ensino e aprendizagem que cheguem ao ideal ou próximo disso (BEHAR, 2020), contudo é necessário que o planejamento estratégico em situação emergencial resultem em ações eficazes e rápidas, atendam demandas urgentes e deve ser objetivo, claro e operacional, de modo a responder prontamente, apresentando caminhos e soluções viáveis (GARCIA et al., 2020). Neste contexto, o referido estudo parte da seguinte problemática: "Os estudantes do $9^{\circ}$ ano têm desenvolvido as atividades pertinentes ao ERE da disciplina Língua Portuguesa de forma a favorecer sua aprendizagem? Diante dessa questão, sugere-se que embora as professoras de 
Língua Portuguesa do $9^{\circ}$ ano ofertem diversas formas de atividades em diferentes canais para comunicação, a maioria dos estudantes de limitam a assistirem as aulas síncronas/assíncronas, pouco interagindo com os conteúdos e compartilhando informação e, apenas a minoria desses estudantes desenvolvem as atividades impressas e comparecem a escola para sanar suas dúvidas com a professora.

Acredita-se que na prática cotidiana o tempo que os estudantes se dedicam a assistirem as aulas remotas é bem menor, pois é sabido que existem inúmeros fatores que têm desviado a atenção dos estudantes da aula remota, a exemplo das redes sociais, programas de TV, aplicativos de mensagens entre outros atrativos que na sala de aula no modo convencional, ou seja no ensino presencial , esses atrativos não podem ser acessados indiscriminadamente. Por outro lado, também consideramos a ideia de Rolim (202I) ao apontar algumas particularidades do Ensino Remoto emergencial na escola pública, que de forma geral apresentam alguns obstáculos a mais do que o ensino ofertado por instituições particulares e, dos desafios observados nas instituições públicas , pode-se destacar os poucos recursos financeiros de cada família dos estudantes. Situação que pode dificultar o acesso e eficiência do ERE para os estudantes menos abastados financeiramente.

$\mathrm{Na}$ visão de Garcia et al., (2020) o interesse do aluno é um aspecto desafiador para o ensino remoto, pois significa tornar a ambiência da apresentação das aulas tão ou mais atrativa do que aquilo que aluno encontrar disponível na rede de comunicação aberta. Ademais, é imprescindivel compartilhar e problematizar estratégias didáticas, a partir de boas práticas no coletivo que promovem o maior engajamento entre os pares, e que, "mesmo se tratando do ERE, as aulas online possam ser dialógicas e não meramente expositivas" OLIVEIRA, CORRÊA; MORÉS, 2020, p. I6). Neste sentido, justifica-se estudos que geram discussão sobre o ensino remoto, os desafios enfrentados e as estratégias que podem tornar o ERE uma modalidade de ensino que favorece a aprendizagem e assim, buscou-se com este estudo descrever a frequência com que os estudantes os estudantes do $9^{\circ}$ ano interagem com as ações vinculas ao Ensino Remoto Emergencial e se consideram que as aulas de Língua Portuguesa assistidas no ambiente online são boas e favorecem a aprendizagem.

Dessa forma, Valle e Marcom (2020, p. 139), afirmam que os atores educacionais devem "explorar novos horizontes e refletir sobre quais são os nexos existentes entre a prática pedagógica desenvolvida pelo professor e o processo ensino aprendizagem em tempos de isolamento social". Ao compreender como acontece o ERE, analisando a vivência e percepção dos estudantes nesse novo contexto educacional, será possível intervir e tentar reverter ou minimizar os impactos negativos advindos dessa nova forma de ensinar e aprender.

\section{REFERENCIAL TEÓRICO}

\section{O Ensino Remoto Emergencial e a adaptação ao novo modelo de ensino e aprendizagem}

Vivenciamos no mundo inteiro um cenário de readaptação do modo de vida a partir de março de 2019, devido a pandemia causada pelo COVID-19. A partir do pandemia, o mundo foi obrigado a se readaptar para viver e conviver com o distanciamento social e os protocolos indicados pelas agências de saúde para barrar ou minimizar a propagação do Corona Vírus e, nesse contexto todos os setores da sociedade, foram atingidos de alguma forma e, não obstante o setor de educação. 
Em tempos de pandemia, muitos são os entraves que precisam mobilizar opiniões e posições dos governos, a fim de minimizar esses problemas e traçar novas perspectivas. Com a educação básica, entendida como direito público subjetivo e assegurada pela Constituição Federal de 1988, não pode ser diferente (ZAJAC, 2020, p. I)

A situação de emergência originada pelo novo Corona Vírus fez com que muitas instituições educacionais migrassem para o Ensino Remoto Emergencial (ERE) para dar cobertura aos seus estudantes que seguiram o confinamento sem frequentar as aulas de forma convencional. As Escolas tiveram que fechar suas portas e os docentes que estavam acostumados à sala de aula presencial tiveram que se reinventar, pois a grande maioria não estava preparada e nem capacitada para isso (BEHAR, 2020). O Ensino Remoto Emergencial chegou como medida de emergência para dar continuidade ao processo de ensino e, por se caracterizar como um ensino que respeita o distanciamento social, por vezes é confundido com a Educação a Distância.

O Ensino Remoto Emergencial e a Educação a Distância não podem ser compreendidos como sinônimos, por isso é muito importante, no contexto que estamos vivendo, clarificar esses conceitos. O termo "remoto" significa distante no espaço e se refere a um distanciamento geográfico. O ensino é considerado remoto porque os professores e alunos estão impedidos por decreto de frequentarem instituições educacionais para evitar a disseminação do vírus. É emergencial porquê do dia para noite o planejamento pedagógico para o ano letivo de 2020 teve que ser engavetado (BEHAR, 2020, p.2).

Assim, pode-se dizer que o Ensino Remoto Emergencial (ERE) é uma "modalidade de ensino que pressupõe o distanciamento geográfico de professores e alunos e foi adotada de forma temporária nos diferentes níveis de ensino por instituições educacionais do mundo inteiro para que as atividades escolares não sejam interrompidas" (BEHAR, 2020, p.3), Contudo, vale destacar que:

\footnotetext{
$\mathrm{Na}$ literatura educacional não existe escritura sobre o termo "ensino remoto emergencial", uma vez que, diante do contexto a pandemia do novo coronavírus (Sars-CoV-2), é uma experiência extremamente nova. As atividades pedagógicas não presenciais (APNP) não devem ser, portanto, consideradas como modalidade ensino, uma vez que se constituem como alternativa para a manutenção do processo de ensino e aprendizagem até pouco tempo realizado na modalidade presencial (COSTA, 2020, p.8).
}

Ensinar remotamente não é sinônimo de ensinar a distância, embora esteja diretamente relacionado ao uso de tecnologia e, nesse caso, digital (GARCIA et al., 2020, p. 3). O ensino remoto pode ser aplicado por diferentes caminhos que incluem plataformas educacionais ou abertas para outros fins, todavia o fator que vai implicar na variabilidade dos recursos e das estratégias bem como das práticas, estão associados a familiaridade e a habilidade do professor com tais ferramentas. De acordo com Oliveira, Corrêa e Morés (2020) nas aulas da modalidade online, os professores precisam abordar elementos ligados ao cotidiano dos alunos, discutindo inclusive a situação de pandemia vivida, de maneira a explorar a dimensão educativa, pedagógica e científica, assim como instigar motivações que os mobilizem a aprender em caráter colaborativo, incluindo a interação: família-aluno; professor-aluno e aluno-aluno. 
É fato que estamos vivenciando um momento atípico na educação e que a instrumentalização nesse momento é importante para que os professores consigam dar conta de ensinar com a mediação das Tecnologias Digitais, contudo vale destacar que:

Discutir o processo de formação docente e as Tecnologias Digitais Interativas nele envolvidas possa contribuir para possíveis modos de levar os docentes não somente à reflexão, mas à possível ressignificação de suas práticas pedagógicas em tempos de pandemia de Covid-I9, (OLIVEIRA, CORRÊA; MORÉS, 2020, p. 4)

Ao estudar aspectos formação docente e tecnologias digitais utilizadas no Ensino remoto emergencial em tempos de COVID-ı9, Oliveira, Corrêa e Morés (2020), verificaram a importância da formação docente para adquirir novas habilidades que são necessárias para desenvolver Ensino remoto emergencial em tempos de COVID-i9 e destacam a necessidade de ofertar espaços digitais para a interação entre docentes e um repositório digital para o compartilhamento de conteúdo de aulas entres docentes, o que representaria a diminuição da sobrecarga de trabalho. Todavia, Behar (2020) deixa claro que a maior parte das instituições de ensino não está conduzindo o processo de ensino através de Educação a Distância, e sim no Ensino Remoto Emergencial. Esse novo modelo de ensinar "a distância" para cumprir as recomendações de saúde em tempos de pandemia, tem resultado em pressões sobre os professores, pois conforme Zajac (2020) em várias escolas, principalmente nas escolas particulares, onde:

\footnotetext{
As gestões têm feito professores sistematizarem leituras, providenciarem materiais inéditos e recursos de apoio, estarem à disposição para dúvidas, produzirem vídeoaulas e transmissões ao vivo. Muitos docentes, além de não ter o preparo para tal atividade, estão sendo cobrados para melhorar sua linguagem, dinamismo, e se ater mais ao tema da aula. Para manter a cobrança das mensalidades, as escolas têm atendido cada vez mais os pedidos dos pais, reforçando ainda mais a visão mercadológica da educação (ZAJAC, 2020, p. I)
}

Percebe-se então que os estudantes e professores têm passado por desafios variados, pois a pandemia já é um importante desafio a ser vencido (senão o maior desafio), o professor precisou se reinventar em suas práticas pedagógicas e os estudantes tiveram que se ajustar ao novo modelo de estudar e aprender e ambos tiveram que se adaptar na sua forma de viver. Vale destacar que reinventar as práticas pedagógica de forma planejada e sequenciada, seria o ideal, porém em momentos de emergência, não há tempo hábil para planejar, apenas aplicar o que foi rapidamente "pensado" para ser adotado de forma horizontal, desconsiderando o nível de habilidade da turma e a familiaridade dos professores com os recursos indicados pela Escola/Secretaria de Educação.

\section{MARCO METODOLÓGICO}

O estudo caracteriza-se como uma pesquisa de campo, de natureza descritiva e com abordagem qualiquantitativa. O campo da pesquisa foi a Escola Municipal Mário da Mota Limeira, situada no município de Riacho das Almas, no estado do Pernambuco. Os sujeitos pesquisados foram 54 estudantes do $9^{\circ}$ ano, sendo contemplado ir estudantes do $9^{\mathrm{O}} \mathrm{A}$, I5 estudantes do $9^{\circ} \mathrm{B}$, is estudantes do $9^{\circ} \mathrm{C}$ e 13 estudantes do $9^{\circ} \mathrm{D}$. Destaca-se que o referido estudo faz parte do trabalho de Dissertação de Mestrado em Ciências da Educação o qual foi submetido à apreciação quanto aos aspectos éticos da pesquisa através da Plataforma 
Brasil/Comitê de Ética em Pesquisa e aprovado conforme CAAE: 45746621.0.00oo.9227 e № do Parecer Consubstanciado do CEP: 4.755.882.

O instrumento utilizado para a coleta dos dados foi o Google Forms que é um aplicativo de gerenciamento de pesquisas lançado pelo Google Corp. e sua aplicação acontece via web.As questões apresentadas no formulário foram específicas para o Ensino Remoto Emergencial na Disciplina de Língua Portuguesa.

A partir dos dados coletados, procedeu-se a análise de cada questão, onde as respostas foram agrupadas considerando cada turma. No aspecto quantitativo, os dados foram tabuados em planilha de cálculo e a partir dessa tabulação, foram construídos tabela e gráfico com os resultados apresentados em percentual.

\section{RESULTADOS E DISCUSSÕES}

A Constituição Federal (Brasil, 1988) preconiza que TODOS têm o direito a Educação e assim Badin, Pedersetti e Silva (2020), complementam que as novas formas de ensinar e aprender adaptadas a partir da pandemia do Covid-ı, trouxe novas formas de interação que nunca haviam sido praticadas na Educação Básica, e com isso "os sistemas de ensino foram impelidos abruptamente a tomarem medidas para que nenhum aluno ficasse desamparado, seja no seu direito à vida, seja no seu direito à educação" (p. 126).

Corroboramos com Badin, Pedersetti e Silva (2020) ao afirmar que até pouco tempo atrás, no ensino básico brasileiro concebia-se inviável aplicar um projeto pedagógico onde as atividades fossem enviadas para os alunos desenvolverem em casa, afastados de seus pares e sem o acompanhamento do professor, entretanto, devido ao período de pandemia que enfrentamos desde 2020, essa ação teve que ser aplicada.

As mudanças causadas no sistema educacional devido as circunstâncias pandêmicas vivenciadas exigiram das escolas, professores, estudantes e familiares novas posturas para que, trabalhando em conjunto os envolvidos pudessem minimizar os impactos da paralisação das aulas no sistema presencial. Com isso, professores e estudantes tiverem que se adaptar a essa nova modalidade de ensino aprendizagem e neste sentido foi solicitado que os estudantes indicassem a frequência que participam de ações vinculadas ao Ensino Remoto Emergencial (Tabela I).

Tabela I. Frequência que os estudantes da Escola Municipal Mário da Mota Limeira desenvolvem as ações vinculadas ao Ensino Remoto Emergencial. Riacho das Almas-PE, 202I.

\begin{tabular}{|c|c|c|c|}
\hline \multicolumn{4}{|c|}{ Frequência que acontece } \\
\hline Turmas/ Ações & \multicolumn{2}{|c|}{ Assistem a aula síncrona “ao vivo” } \\
\hline & Sempre & Às vezes & Nunca \\
\hline Turma A & $72,7 \%$ & $27,3 \%$ & 0 \\
\hline Turma B & $73,3 \%$ & $26,7 \%$ & 0 \\
\hline Turma C & $46,7 \%$ & $46,7 \%$ & $6,7 \%$ \\
\hline Turma D & $53,8 \%$ & $30,8 \%$ & $15,4 \%$ \\
\hline & Interagem na aula remota (perguntando e dando \\
& \multicolumn{4}{|c|}{ opinião) } \\
\hline Turma A & $45,5 \%$ & $54,5 \%$ & 0 \\
\hline Turma B & $20 \%$ & $60 \%$ & $20 \%$ \\
\hline
\end{tabular}




\begin{tabular}{|c|c|c|c|}
\hline Turma C & $6,7 \%$ & $46,7 \%$ & $46,7 \%$ \\
\hline Turma D & $30,8 \%$ & $46,2 \%$ & $23,1 \%$ \\
\hline & \multicolumn{3}{|c|}{ Interagem por outros meios (Ex: WhatsApp) } \\
\hline Turma A & $36,5 \%$ & $54,5 \%$ & $9,1 \%$ \\
\hline Turma B & $60 \%$ & $40 \%$ & $\mathrm{o}$ \\
\hline Turma C & $53,3 \%$ & $26,7 \%$ & $20 \%$ \\
\hline \multirow[t]{2}{*}{ Turma D } & $30,8 \%$ & $61,5 \%$ & $7,7 \%$ \\
\hline & \multicolumn{3}{|c|}{$\begin{array}{l}\text { Comparecem na escola para tirar dúvidas com a } \\
\text { professora }\end{array}$} \\
\hline Turma A & $9, \mathrm{I} \%$ & $9, \mathbf{1} \%$ & $8 \mathrm{I}, 8 \%$ \\
\hline Turma B & $6,7 \%$ & $6,7 \%$ & $86,7 \%$ \\
\hline Turma C & oo & $33,3 \%$ & $66,7 \%$ \\
\hline \multirow[t]{2}{*}{ Turma D } & $7,7 \%$ & $7,7 \%$ & $84,6 \%$ \\
\hline & \multicolumn{3}{|c|}{$\begin{array}{c}\text { Desenvolvem as atividades complementares que sã } \\
\text { indicadas (Ex: leituras) }\end{array}$} \\
\hline Turma A & $36,4 \%$ & $63,6 \%$ & $\mathrm{o}$ \\
\hline Turma B & $73,3 \%$ & $20 \%$ & $6,7 \%$ \\
\hline Turma C & $66,7 \%$ & $26,7 \%$ & $6,7 \%$ \\
\hline \multirow[t]{2}{*}{ Turma D } & $61,5 \%$ & $23,1 \%$ & $15,4 \%$ \\
\hline & \multicolumn{3}{|c|}{ Desenvolvem as atividades impressas } \\
\hline Turma A & $36,4 \%$ & $36,4 \%$ & $27,3 \%$ \\
\hline Turma B & $33,3 \%$ & $26,7 \%$ & $40 \%$ \\
\hline Turma C & $20 \%$ & $53,3 \%$ & $26,7 \%$ \\
\hline Turma D & $23,1 \%$ & $23,1 \%$ & $53,8 \%$ \\
\hline
\end{tabular}

Fonte: Dados da pesquisa de campo (2021)

As aulas no Ensino Remoto Emergencial podem acontecer de forma síncrona, aquela onde o estudante assiste a aula transmitida com o professor presente de forma remota e nesse momento ele interage simultaneamente e a professora pode responder suas dúvidas ou aula assíncrona, em que se disponibiliza a aula gravada e o estudante pode assistir em outro horário que não seja específico dessa aula. Observa-se na Tabela i que a maioria dos estudantes das turmas $\mathrm{A}(72,7 \%)$ e $\mathrm{B}(73,3 \%)$ indicaram que sempre participam da aula síncrona. Nas turmas $\mathrm{C}$ e $\mathrm{D}$, obteve-se menores percentuais de estudantes que sempre assistem as aulas síncronas $(46,7 \%$ e $53,8 \%$, respectivamente) e constatou-se que $6,7 \%$ e $15,4 \%$ dos estudantes das turmas $\mathrm{C}$ e $\mathrm{D}$, respectivamente informaram que nunca assistem as aulas síncronas. Ademais foi solicitado que os estudantes justificassem suas respostas e os argumentos apresentados variaram entre: tempo disponível para a aula, disponibilidade de internet para acessar as aulas, melhor forma de aprender, entre outros motivos que viabiliza assistir a aula síncrona ou assíncrona:

Turma A-E3: "Sempre assisto ao vivo, para interagir e tirar minhas dúvidas"

Turma A-E4: "Tenho muitos afazeres"

Turma B-Eıo: "Assisto depois, pois acho melhor."

Turma B-EI2: "Cria uma rotina e acaba sendo melhor para estudar" 
Turma C-E2: "As vezes assisto em outro momento quando a internet esta disponível mas e ruim porque se assisto uma mas tem outras que ta pra assisti e fazer."

Turma C-E3: "Tipo quando não estou costurando eu assisto ela na hora da Live, mas quando eu tô deixa para assistir à noite".

Turma C-Eıo: "Eu gosto mais de assistir as aulas depois que já tem terminado mais eu sempre faço as atividades"

Turma D-E9: "Não que assistir em tempo real seja ruim, e so eu prefiro fazer em outro momento gosto mais de fazer as atividades a noite!"

Turma D-Eız: "Assistir ao vivo demora muito e as vezes não carrega bem ao vivo."

A interação entre professores e estudantes, estudante e conteúdo ministrado e estudante com seus pares, são aspectos importantes para eficiência do processo de ensino e aprendizagem. Assim, ao perguntar a frequência que os estudantes interagem na aula remota, observou-se os números mais expressivos de estudantes, representados pelos maiores percentuais (Turma A: 54,5\%; Turma B: 60\%; Turma C:46,7\% e Turma D:46,2\%) indicaram que somente "ás vezes" é que interagem na aula fazendo perguntas ou opinando sobre aspectos do conteúdo ministrado.

Não é raro, vivenciarmos as diversas formas de interação dos jovens nas redes sociais, sejam através de trocas de mensagens, gravação e comentários de vídeos e áudios, entre outras ações que envolve os recursos tecnológicos. Nesta ótica, Quirino (2020) levanta um questionamento: "Por que uma parcela da população/estudantes tem o acesso, mas não fazem/interagem com os professores? E o autor ainda destaca a necessidade de percebermos a forma que os jovens fazem uso da internet e dos recursos tecnológicos, para que a partir do que gostam e vivenciam, possamos nos aproximar desses jovens estudantes.

Corroboramos com a ideia apresentada por Badin, Pedersetti e Silva (2020) quando nos afirma que a escola é o lugar da convivência. Os espaços e práticas escolares sempre foram pensados para favorecer a interação e o aprendizado a partir da experiência concreta. Assim, diante da impossibilidade dos estudantes interagirem na escola (local físico) e sabendo da importância de haver alguma forma de interação, deve-se buscar diferentes alternativas para estimular o estudante a interagir com o contexto educacional, incluindo os colegas de turma, as aulas, os conteúdos e atividades paralelas vinculadas ao ERE. Nesta ótica, verifica-se na Tabela I que a frequência que os estudantes interagem nos grupos de aplicativo de mensagens foi bem variada, sendo que a maioria dos estudantes das Turmas $B$ (6o\%) e C (53,3\%) afirmaram que sempre buscam a interação nos grupos, por outro lado a maioria dos estudantes das Turmas A $(54,45 \%)$ e D $(61,5 \%)$ indicaram que somente "às vezes" interagem nos grupos formados pelas professoras de Língua Portuguesa.

Ao avaliar o Ensino Remoto Emergencial desenvolvido em escolas públicas no estado do Ceará, no período da pandemia do Covid-ı, Rolim (2012) afirma a necessidade de aplicar estratégias para que os estudantes, mesmo distantes presencialmente da escola, possam ter o suporte para dar continuidade aos estudos. $O$ autor identificou que vários grupos de WhatsApp foram formados por turmas e turnos para fortalecer o elo entre as partes interessadas e esse aplicativo foi muito útil para o envio das atividades aos discentes e reenvio para os discentes. 
Devido o ERE ter sido adotado de forma repentina, muitas adaptações tiveram (e ainda têm) que ser realizadas. $O$ acompanhamento/monitoramento do processo de aprendizagem dos estudantes é realizado de forma mais eficiente quando o processo acontece de forma presencial, mas devido a pandemia do Covid-ı e a necessidade de evitar aglomerações, mantendo o distanciamento social, isso ainda não é possível, entretanto a escola campo da pesquisa, adotou uma ação na qual é possível o estudante marcar previamente um horário com a professora e realizar um "reforço" ao conteúdo que foi ministrado, de forma que se possa favorecer a aprendizagem. Destaca-se que nessa ação é considerada as medidas de segurança tanto para a professora quanto para o estudante que vai à escola buscar esse reforço. Mesmo assim, percebe-se nos dados apresentados na Tabela I que a maioria dos estudantes das Turmas: A (81,8\%); B (86,7\%); C (66,7\%) e D (84,6\%) indicaram que nunca foram a escola (nesse período de pandemia) para tirar dúvidas com a professora de Língua Portuguesa.

Ao estudar as principais dificuldades de professores e alunos em relação as aulas remotas ofertadas por instituições públicas nos níveis fundamentais e médios, Miranda et al., (2020) verificaram que os estudantes ao avaliar seu processo de aprendizagem embasada nas atividades relacionadas ao ensino remoto, consideraram sua aprendizagem regular ou até mesmo insatisfatória. As referidas autoras atribuem essa aprendizagem "não desejada", aos fatores que geram dificuldades para que o processo aconteça com eficiência, a exemplo de: falta de motivação e de um local adequado para estudar, fatores que dificultam a compreensão dos conteúdos, falta de rotina e organização dos horários de estudos como também a forma de explicação dos conteúdos que não atende as necessidades.

Constatou-se que a maioria dos estudantes das turmas B, C e D (73,3\%; 66,7\% e 61,5\%, respectivamente) informaram que sempre realizam as atividades complementares que são indicadas, contudo apenas $34,5 \%$ dos estudantes da turma $\mathrm{A}$, indicaram realizar as atividades complementares com frequência (Tabela I).

As atividades impressas fazem parte do pacote de atividades desenvolvidas no Ensino Remoto Emergencial e aqueles estudantes que não possuem acesso ou têm acesso limitado a internet ou recursos para ter o acesso as aulas, podem focar nas atividades impressas, embora seria melhor que essas atividades fossem desenvolvidas em paralelo as aulas síncronas/assíncronas do ERE. No referido estudo, foi verificado que no geral, os estudantes que participaram do estudo sentem algum nível de dificuldades para desenvolver as atividades impressas e os quantitativos se resumem em: Turma A (54,5\%); Turma B $(20 \%), C(46,7 \%)$ e D (46\%) apresentam níveis de dificuldades variando em pouca a muita dificuldade para realizar as atividades impressas e alegaram que para superar essas dificuldades buscam:

Turma A-E6: "Procuro ajuda"

Turma A-Eıo: "Bom eu tento superar as minhas dificuldades refazendo as coisas quantas vezes forem possíveis.."

Turma B-EI: "Eu pesquisa no YouTube pq eu não sabia quem era meus professores"

Turma B-E6: "Perguntar e tirar dúvidas com a professora ou professor".

Turma C-Er: "O problema de vim impressas e que, se a pessoa tem dificuldade de entender ela vai está toda hora perguntando a 
Revista Ibero- Americana de Humanidades, Ciências e Educação- REASE open Access $^{\text {acs }}$

professora uma explicação e são em média de 20+ alunos perguntando, as remotas com um vídeo explicativo já é o bastante!”. Turma C-Ei4: "Falo com algum professor pra tentar me ajudar"

Turma D-E3: "Só tenho mais em matemática"

Turma D-Eıo: "Se virar sozinho".

Denota-se nos argumentos apresentados pelos estudantes que buscam superar as dificuldades para desenvolver as atividades impressas que existe um anseio em superar tais dificuldades e conseguir realizar as atividades mesmo que tenham que buscar ajuda, tentar repetidas vezes, mesmo de sozinhos e, outros buscam a ajuda de professores ou sites da internet.

O ERE não se resume às aulas remotas, pois várias outras ações são desenvolvidas, levando em consideração o distanciamento social e objetivo de promover a aprendizagem dos estudantes. Neste sentido os estudantes das quatro turmas estudadas foram indagados a respeito das ações que as professoras de Língua Portuguesa desenvolvem no sentido de facilitar a aprendizagem $e$ as respostas apresentadas foram bem variadas, entretanto o sentido das respostas obtidas converge para os argumentos apresentados na Figura I.

Figura I. Representação em forma de "nuvem de frases", criada a partir da convergência de ideias expressadas pelos estudantes da Escola Municipal Mário da Mota Limeira sobre as ações desenvolvidas pelas professoras de Língua Portuguesa para fortalecer o processo de aprendizagem através do ERE. Riacho das Almas-PE, 2021.

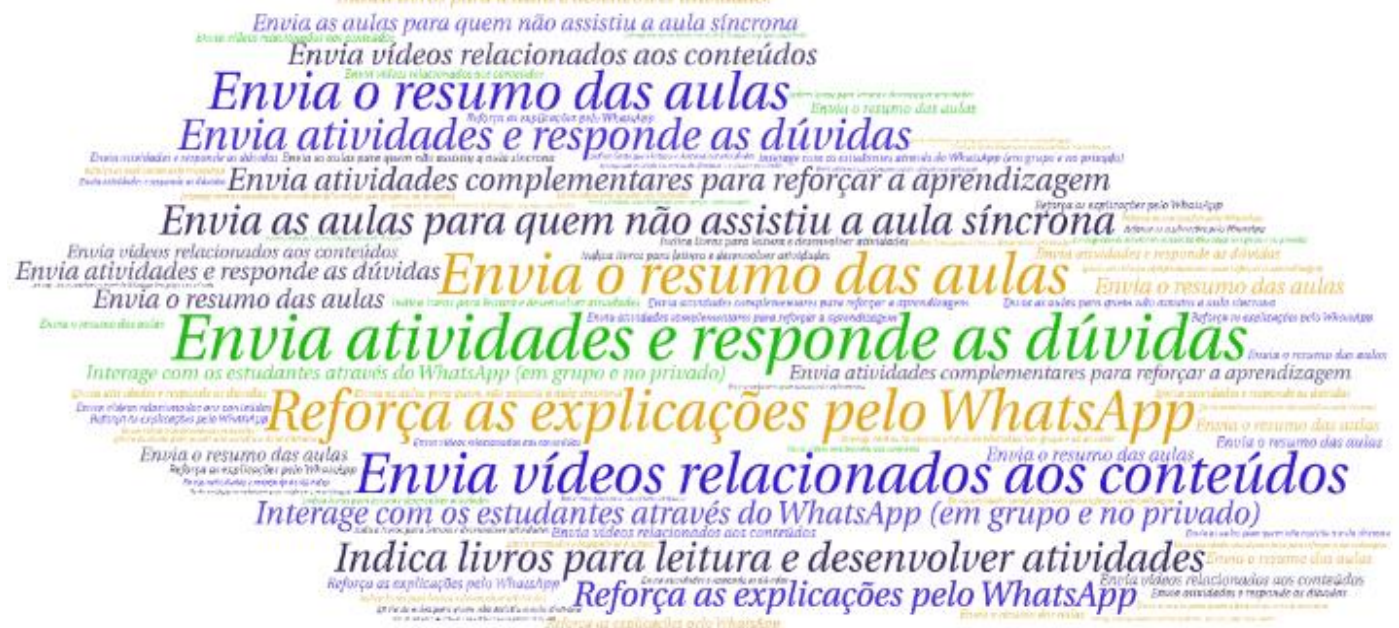

Nuvem de frases criada através do wordart (disponível em: (https://wordart.com/create)

Verifica-se na Figura I, que as atividades que as professores de Língua Portuguesa desenvolvem em paralelo ao Ensino Remoto Emergencial, podem ser resumidas em: envio de atividades extra; responder as dúvidas dos estudantes; enviar um resumo das aulas ministradas de forma remota; reforçar as explicações pelo WhatsApp; enviar vídeos relacionados aos conteúdos; enviar as aulas gravadas para quem não conseguiu assistir a aula síncrona; interagem com os estudantes através do WhatsApp (em grupo e no privado); envia atividades complementares para reforçar a aprendizagem dos estudantes e fazem a indicação de livros para leitura e desenvolver atividades. Dessa forma pode-se afirmar que as ações 
vinculas ao ERE são diversificadas com diversas formas de atividades e canais de comunicação onde as professoras se utilizam para promover a qualidade no processo de ensino e aprendizagem em tempos de pandemia e de obrigatoriedade em manter o distanciamento social.

O Ensino Remoto Emergencial trouxe novas formas de desenvolver o ensino formal, onde a forma de ensinar e aprender foram ajustadas. O ensino remoto envolve várias ações que não somente aquela de aulas síncronas e assíncronas, e essas ações incluem atividades complementares que podem ser entregues através de aplicativos, e-mail e/ou outras formas a ser combinada entre estudantes e escola/professores.

No modelo de escola que conhecemos, existe a interação entre o professor e os estudantes, entre estudantes com seus pares e o professor como mediador, de forma geral estimula o estudante interagir com os conteúdos e àqueles professores mais experientes, já notam no olhar dos seus alunos quando o conteúdo está compreensível e sendo assimilável pela turma. Situação que, no ERE fica difícil, uma fez o contato presencial não pode acontecer com a turma completa e quando o estudante procura a escola para falar com a professora, isso deve acontecer respeitando o distanciamento, o uso de máscaras e sem contato físico como um simples aperto de mão, conforme medidas de segurança recomendadas por agentes de saúde. Todas essas adaptações, possivelmente causa desconforto para os envolvidos e pode gerar uma situação não favorável para o processo de ensino aprendizagem.

De acordo com Badin, Pedersetti e Silva (2020) em tempos de pandemia para ofertar um ensino de qualidade para estudantes de educação básica, deve-se compreender a importância da "interação, o olhar, a proximidade, o toque e todos esses aspectos precisam ser reinventados, dada a impossibilidade de aproximação exigida para o controle da pandemia" (p.125). Neste contexto foi perguntado aos estudantes se as aulas do Ensino Remoto Emergencial ERE promove boas aulas e favorece a aprendizagem (Gráfico I).

Gráfico I. Concepção dos estudantes da Escola Municipal Mário da Mota Limeira a respeito ERE promover boas aulas e a aprendizagem. Riacho das Almas-PE, 202I.

\section{ERE promove boas aulas e aprendizagem}

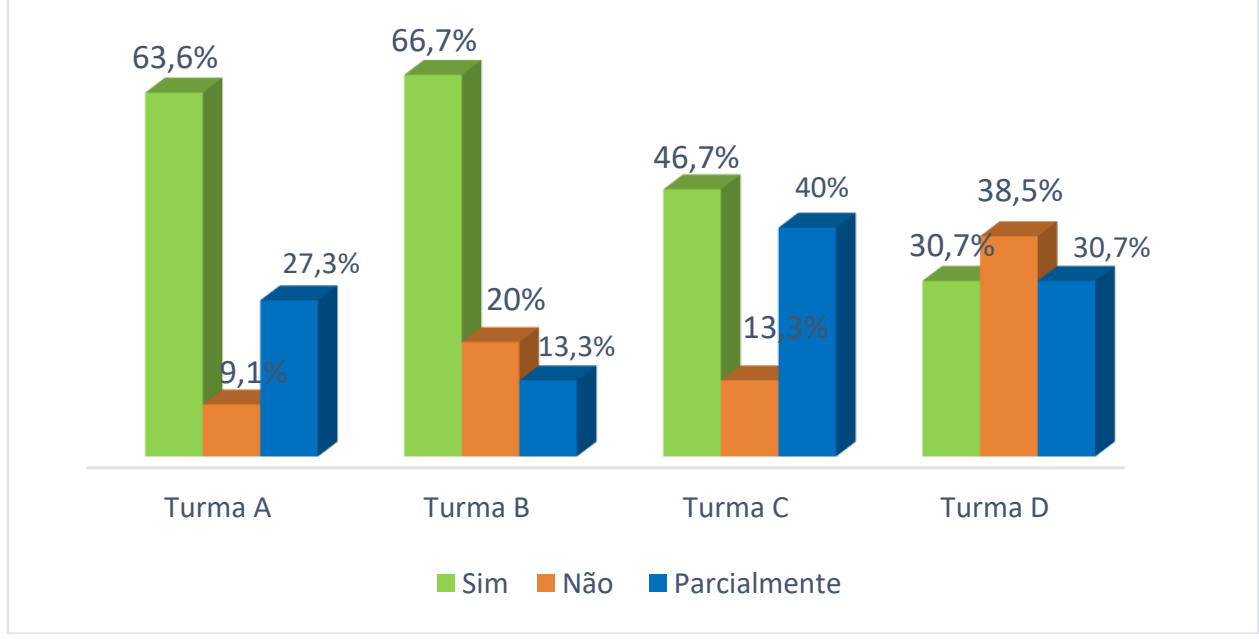

Fonte: Dados da Pesquisa de campo (202I) 
Percebe-se nos dados apresentados no Gráfico 8 que a maioria dos estudantes das Turmas A $(63,6 \%)$ e B $(66,7 \%)$ consideram que o Ensino Remoto Emergencial tem promovido boas aulas e a aprendizagem, entretanto na Turma C, apenas $46,7 \%$ dos estudantes compartilham dessa ideia, divergindo de $38,5 \%$ dos estudantes da turma $\mathrm{D}$ que sinalizaram o contrário, ou seja concebem que o ERE não promove boas aulas e a aprendizagem e essa concepção também foi afirmada por 9,1\%, 20\% e 13,3\% dos estudantes das turmas $\mathrm{A}, \mathrm{B}$ e $\mathrm{C}$, respectivamente e dos argumentos apresentados pelos estudantes, destacam-se:

Turma A-E3: "Nos estudantes intendemos mais ou menos, não é a mesma coisa que as aulas presenciais mais dá para entender alguns assuntos."

Turma A-E7: “Tem assuntos que são mais fáceis de tratar. Já outros que cada aluno precisaria de um auxílio específico. Não acho que os professores dão conta sempre. Pois entendendo que estão tendo bastante trabalho nesse meio."

Turma A-Eıo: Bom, dar pra entender mais não da pra aprender pois não tem a eficiência do professor explicando pois na sala de aula a gente quando tem uma duvida a gente pergunta pra o professor, a mais você deve estar pensando mais nas aulas online da para fazer isso ,da mais na sala de aula o professor responde sua pergunta quantas vezes forem necessária para o aluno entender .

Turma B-Eıo: "Presencialmente o ensino é mais simplificado e mais fácil de compreender."

Turma B-Eı2: "O tempo de aula é muito curto, o ambiente da sala de aula traz melhor concentração.".

Turma B-Eıs: "Porque não e a mesma coisa do que está na sala de aula e também não consigo entende nada".

Turma C-EI: "Não e tão eficiente por 2 motivos, primeiro a falta de explicação, claro tem os vídeos lives texto pra explicar mais não se compara com um professor em sala de aula, segundo o Google acredito que $60 \%$ dos alunos usa pra obter respostas!”.

Turma C-E2: "O ensino presencial e bem melhor porque estamos lado a lado dos professores mas nao a muitas dificuldades no ensino remoto."

Turma C-E5: "Parcialmente. Porque as aulas então sendo boas. Mas que eu como aluna não estou aprendendo muito o conteúdo como antes. Agora é um pouco mais difícil de entender os conteúdos das matérias."

Turma D-Eı: "Eu entendo que é precioso, mais tipo acho que bastante gente tem dificuldade"

Turma D-E4: "Porque não tem a mesma explicação das aulas presenciais exemplo com migo mesma nao entendo tudo tenho bastante dificuldade pra entender as atividades e etc.".

Turma D-E5: "Eu acho que pela internet é legal e tudo mais, só que agente se complica muito eu acho que as aulas deveriam voltar presencial." 
Turma D-E9: "Na minha opinião os estudos presenciais trazem uma melhor experiência para o aluno.”

O processo de ensino deve ter como prioridade a aprendizagem e pode-se perceber nos argumentos apresentados pelos estudantes que o ERE tem causados para uma parcela desses estudantes, algumas insatisfações, embora a maioria dos estudantes das turmas A e B considerem que as aulas são boas e favorece a aprendizagem. Verifica-se nos argumentos dos estudantes, o desejo do retorno das aulas presenciais, pois alegam os estudantes que a explicação do professor em sala de aula (presencial) é fundamental para a compreensão dos conteúdos; na sala de aula o professor pode explicar e repetir a explicação de varias formas, até que o estudante compreenda o assunto abordado; a aula presencial é mais simples, favorece a concentração e a aprendizagem; além do mais a aula presencial propicia uma melhor experiencia para o estudante.

É possível inferir que o ERE não favorece a aprendizagem para uma parcela de estudantes das turmas avaliadas e continuando a análise dos argumentos apresentados por esses estudantes, pode-se afirmar que alguns estudantes sentem muitas dificuldades para compreenderem os conteúdos, outros compreendem apenas uma parte desse conteúdo. Alunos também reivindicaram mais suporte e apoio pedagógico, pois alegam que nas aulas é possível entender, mas não aprender, além disso as atividades por serem realizadas fora do ambiente escolar pode naturalmente serem copiadas da internet e isso apenas se traduz em "copiar e colar" sem a preocupação de estar fazendo o correto, treinando e aprendendo os conteúdos ministrados.

Inúmeros foram os impactos causados pela pandemia do Covid-ı́ e não há como mensurar todos os impactos gerados a todos os setores da sociedade e sua dimensão, uma vez que é possível que determinados impactos só possam ser sentidos (ou agravados) em longo prazo ou posterior ao período de pandemia.

O ERE foi adaptado para o ensino regular no período de pandemia, todavia esse ensino apresentou algumas particularidades entre escolas municípios/estados da federação brasileira, ou seja algumas escolas disponibilizaram plataformas de estudo e vídeo aulas, enquanto outras escolas e outros professores improvisaram aulas por plataformas de acesso livre que são gratuitas e poderiam ser acessadas através de smartphones, tablets, desktop, notebook etc, entretanto o que não se pode negar é que houve uma "força tarefa" envolvendo gestores, diretores, professores e demais atores educacionais no sentido de minimizar os impactos da pandemia no sistema educacional brasileiro.

\section{CONCLUSÕES}

O processo de ensino aprendizagem formal e convencional inclui aquele que é mediador (o educador) da aprendizagem e aquele que aprende (embora também ensina). Para que o Ensino Remoto Emergencial desenvolvido pelos educadores favoreça a aprendizagem dos educandos do $9^{-}$ano da Escola Municipal Mário da Mota Limeira, é necessário que haja interação entre os envolvidos no processo. No referido estudo verificouse que que não são todos os estudantes das turmas pesquisadas que assistem a aula síncrona da disciplina Língua Portuguesas e, dos estudantes que assistem aulas síncronas, nem metade desse total interagem com frequência no momento da aula. 
Inúmeros foram os impactos causados pela pandemia do Covid-ı́ e não há como mensurar todos os impactos gerados a todos os setores da sociedade e sua dimensão, uma vez que é possível que determinados impactos só possam ser sentidos (ou agravados) em longo prazo ou posterior ao período de pandemia, contudo ficou claro que as atividades impressas não estão na lista de prioridades dos estudantes que participaram do estudo pois percentuais entre $27 \%$ e $54 \%$ dos estudantes afirmaram que nunca desenvolvem as atividades impressas e de forma geral alegam sentir algum nível de dificuldade, entretanto e paradoxalmente apenas um reduzido número de estudantes (entre o a $9 \%$ ) procuram a escola e tentam sanar as dúvidas com a professora de Língua Portuguesa.

Os estudantes relataram que as atividades vinculadas ao ERE são diversificadas e podem ser compartilhadas, assistidas, lidas ou estudadas através de diferentes canais de comunicação e no horário propicio ao estudante, entretanto percentuais que variam entre 7 e $15 \%$ dos estudantes indicaram que nunca realizam as atividades de leitura indicado pela professora, além disso, percentuais que representam de 8 a 20\% dos estudantes afirmaram que nunca interagem nos grupos do WhatsApp formados com objetivo de sanar as dúvidas, compartilhar informações/conteúdos, resumo, vídeos e material que possa fortalecer a aprendizagem.

Considerando que das turmas pesquisadas, percentuais expressivos de estudantes indicaram que o ERE promovem boas aulas e a aprendizagem, percebe-se que existe uma falta de motivação por parte dos estudantes para participarem ativamente e frequentemente das ações vinculadas ao ERE e, espera-se adquirir novas compreensões sobre o processo de ensinar e mediar a aprendizagem de forma remota, considerando as estratégias que tem apresentado bons resultados e àquelas que precisam ser repensados para tornar o ERE mais eficiente.

Ao identificar algumas questões que permeiam o Ensino Remoto emergencial e a aprendizagem dos estudantes do $9^{\mathcal{O}}$ ano do ensino fundamental II, especificamente no que se refere a disciplina de Língua Portuguesa ofertada Escola Municipal Mário da Mota Limeira, estar-se-á contribuindo para uma reflexão quanto a essa forma de ensinar e aprender e, partir em busca de estratégias que possam estimular a motivação dos estudantes para se envolverem efetivamente com o processo de ensino e aprendizagem.

\section{REFERÊNCIAS BIBLIOGRÁFICAS}

BADIN, ANA MARIA ANDREOLA.; PEDERSETTI, SIMONE.; SILVA, MELISSA BORGES da. Educação básica em tempos de pandemia: tentativas para minimizar o impacto do distanciamento e manter o vínculo entre os alunos, as famílias e a escola. In: PALÚ, JANETE.; SCHÜTZ, JENERTON ARLAN.; MAYER, LEANDRO (Ogs). Desafios da educação em tempos de pandemia, Ed. Ilustração, 2020. 324p, Cruz Alta. p 121-137. BEHAR, PATRICIA ALEJANDRA. O Ensino Remoto Emergencial e a Educação a Distância. Jornal da Universidade, Faculdade de Educação, UFRGS , Artigo publicado em o6 de julho de 2020, Disponível em https://www.ufrgs.br/coronavirus/base/artigo-oensino-remoto-emergencial-e-a-educacao-a-distancia/. Acesso em i2 de fevereiro de 202I.

COSTA, KÁTIA ANDRÉA SILVA da. EAD, Ensino Híbrido e Ensino Remoto Emergencial: perspectivas metodológicas. DIRAC/PROENS. Curitiba, PR, 2020. 
GARCIA, TÂNIA CRISTINA MEIRA.; MORAIS, IONE RODRIGUES DINIZ; ZAROS, LILIAN GIOTTO.; RÊGO, MARIA CARMEM FREIRE DIOGENES. Ensino Remoto Emergencial: Proposta de design para organização das aulas. Universidade Federal do Rio Grande do Norte, SEDIS, Natal-RN, 2020. 15p.

QUIRINO, VALKER LOPES. Ensino Remoto: Alguns desafios presentes para os professores da Educação Básica. In: Anais...CONEDU. Congresso Nacional de Educação, VII. Educação como (re)Existência, mudança, conscientização e conhecimentos. MaceióAlagoas , 2020. Disponível em: https://editorarealize.com.br/artigo/visualizar/68535 . Acesso em 30 de junho de 202I.

MIRANDA, KACIA KYSSY CÂMARA DE OLIVEIRA.; LIMA, ALZENIR DA SILVA.; OLIVEIRA, VALESKA CRYSLAINE MACHADO DE.; TELLES, CINTHIA BEATRICE DA SILVA. Aulas remotas em tempo de pandemia: desafios e percepções de professores e alunos. In: Anais...CONEDU. Congresso Nacional de Educação, VII. Educação como (re)Existência, mudança, conscientização e conhecimentos. MaceióAlagoas 2020. Disponível em: https://editorarealize.com.br/editora/anais/conedu/2020/TRABALHO_EVI40_MDI_SA _ID5382_03092020142029.pdf . Acesso em 03 de julho de 2021.

OLIVEIRA, RAQUEL MIGNONI DE.; CORREAA, YGOR.; MORÉS, ANDRÉIA. Ensino remoto emergencial em tempos de COVID-I9: formação docente e tecnologias digitais. Rev. Int. de Form.de Professores (RIFP), Itapetininga, v. 5, e020028, p. I-I8, 2020.

ROLIM, RONNIELlE CABRAL. Avaliação do Ensino Remoto Emergencial mediado pelos professores de ciências da rede pública de Caucaia-Ceará durante a pandemia do Covid-19. Revista Ibero-Americana de Humanidades, Ciências e Educação. São Paulo, v.7.n.4. Maio.2021.ISSN -2675 -3375. Disponível em: https://periodicorease.pro.br/rease/article/view/IIgo/524. Acesso em 22 de junho de 202I.

VALLE, PAULO DALLA.; MARCOM, JACINTA LUCIA RIZZI. Desafios da prática pedagógica e as competências para ensinar em tempos de pandemia. In: PALÚ, JANETE.; SCHÜTZ, JENERTON ARLAN.; MAYER, LEANDRO (Ogs). Desafios da educação em tempos de pandemia, Ed. Ilustração, 2020. 324p, Cruz Alta. p. 139-153.

ZAJAC, DANILO. Ensino remoto da Educação Básica e Covid-ıo: um agravo ao Direito à Educação e outros impasses. Santo André: Escola preparatória de Universidade Federal do $\mathrm{ABC} /$ Pró-reitora de Extensão e Cultura, 2020. Disponível em: https://proec.ufabc.edu.br/epufabc/ensino-remoto-na-educacao-basica . Acesso em os de março de 2021. 